\title{
Learning Strands: Empowering Prospective Teachers for Science Practices in Indian Context
}

\author{
Shashi Prabha ${ }^{1}$, Rakesh Kumar ${ }^{2}$ Arbind K. Jha ${ }^{3}$ \\ National Council of Educational Research and Training, New Delhi, India ${ }^{1}$ \\ MV College of Education, Delhi, India ${ }^{2}$ \\ Central University of Himachal, Dharmashala, India ${ }^{3}$
}

\begin{abstract}
Designing science learning environments as complex and multidimensional process based upon sound conceptual understanding of nature of science and a generative epistemology and pedagogy needs special understanding of scientific inquiry and considering feelings and attitudes of science learners toward science using flexible planning process. This study comprising 20 prospective teachers and 723 learners explored the application of the six strands (proposed for learning in the informal setting) to a formal set-up. Transaction of science lessons applying learning strands provided needed flexibility in planning process to the prospective teachers and generated curiosity, interest among the learners to know something more beyond the textbooks and boundaries of teacher instruction. Science learners were found to be more engaged, participative and reflecting. Enhancement of their epistemic understanding of science is also one of the observations. Most learners have found to be thinking about themselves as learners of science and capable to contribute in the development of science. The study recommends the six learning strands as a resource for refining teacher education program.
\end{abstract}

\section{Introduction}

The pluralistic and diverse nature of learners in a heterogeneous classroom necessitates designing of a variety of teaching learning experiences of science, so as to promote understanding and participation of all. This effect of diversity in the Indian classrooms is reflected in the prospective teacher education settings also. The teacher's own role in children's cognition could be enhanced if they assume a more active role in relation to the process of knowledge construction in which children are engaged [1]. The diversity in the classrooms when celebrated rather than being seen as a hindrance to the teaching -learning process becomes the backbone of the individualized and contextualized attention to the science learner, which is essentially not a case in more traditional learning designs. Today nobody can deny that learners actively construct their own knowledge by connecting new ideas to their existing ideas on the basis of experiences with materials and activities presented to them. Practicing science in such a contextualized setup needs planning and designing science experiences that are in synchronization with these types of assumptions about effective teaching learning strategies.

Learning in informal environments, in 'Taking Science to School: Learning and Teaching Science in Grades K-8'[2] mentions about four learning strand in formal set up for getting proficiency in science. Extending these four learning strands in formal set up to six learning strands in informal set up also, [3] holds the opinion that there is overlapping of learning in the two set ups. These six learning strands are closely intertwined. Strengthening of one learning strand can support the other strands. Similarly weakness of one strand affects the other.

Six learning strands [4]:

- Strand 1: Experience excitement, interest, and motivation to learn about phenomena in the natural and physical world.

- Strand 2: Come to generate, understand, remember, and use concepts, explanations, arguments, models, and facts related to science.

- Strand 3: Manipulate, test, explore, predict, question, observe, and make sense of the natural and physical world.

- Strand 4: Reflect on science as a way of knowing; on processes, concepts, and institutions of science; and on their own process of learning about phenomena.

- Strand 5: Participate in scientific activities and learning practices with others, using scientific language and tools.

- Strand 6: Think about themselves as science learners and develop an identity as someone who knows about, uses, and sometimes contributes to science. perspective on the learning of science [6].

Guiding principle of [1] are; connecting knowledge to life outside the school; ensuring that learning is shifted away from rote methods; enriching the curriculum to provide for overall 
development of children rather than remain textbook-centric; making examination more flexible and integrated into classroom life; nurturing an over-riding identity informed by caring concern within the democratic polity of the country.

The six strands of learning [4] seem to be in consonance with the guiding principles of NCF2005. Learning takes place within school as well as outside the school has been highlighted in NCF2005. Learners' learning is believed to be enriched by integrating their school and outside school experiences as conceptual development has been envisaged as continuous process of deepening and enriching connections and acquiring new dimension of meaning. This paper is an attempt to take the ideas from NCF 2005 ahead, at the planning and science learning experience - lesson design level so that the guiding principles of NCF 2005 and international researches can be used for building science practices that cater to the needs of diverse populations across the globe taking Indian settings as an example.

Learning strands of scientific proficiency represent learning goals for learners and help the teachers to design guidelines of science lesson as a facilitator of learning. These strands empower her/ him to take multidimensional approach in teaching learning process. These are the practices in science that learners need to participate for developing proficiency. It provides a framework for learning science in various dimensions. 'Ready, set science! Putting Research to work in K-8 Science Classroom' says, "strands of proficiency are built on the helpful contributions of science standards documents such as the Benchmarks for Science Literacy and the National Science Education Standards. These documents set out to characterize the conceptual goals of science education and call for greater emphasis on science as inquiry. The strands of proficiency provide a framework for thinking about elements of scientific knowledge and practice. They can be useful to educators in their effort to plan and assess learner learning in classrooms and across school systems. They can also be a helpful tool for identifying the science that is emphasized in a given curriculum guide, textbook, or assessment', [5].

It is important that learners find science education interesting and exciting and something related with their everyday life, existing not only in the science textbooks. The important aspect of the strands is that they are closely intertwined with each other and suggest multiple ways to engage with the concepts in teaching- learning of science. The six strands provided in the box above are related to the need from the science practices learning designs, to incorporate a diverse range of demands in teaching learning of science. Conceiving learning strands at the planning stage of teaching -learning provides flexibility in learning design and creates learning situations in constructivist paradigm. Learning strands can facilitate teachers to engage the learners in construction of their knowledge. The strands seem to map the ideas that learners should know at the end of a lesson. Learning strand also seems to help to plan, explore, transact and assess the concepts.

\section{Context of the study}

Facilitating young learners' teaching learning of science with understanding requires that prospective teachers themselves understand conceptual development framework and the natural curiosity of the science learner to inquire about natural and physical world. In this context, it becomes important for the prospective teachers to know about, pedagogical and assessment alternatives, and scientific, conceptual and procedural knowledge of science. Moreover, in the emerging paradigm of teaching and learning, educating an effective teacher of science is coming to mean much more than presenting innovative ways to teach science. Practicing teachers need a sound conceptual understanding of nature of science and a transformative epistemology and pedagogy of their perspective on learning science [6]. The constructivist approach on science learning recognizes that science knowledge is not something a teacher transfers to learners. Meaningful learning is a generative process of representing and manipulating concrete things and mental representations, rather than storage and retrieval of information. At the upper primary stage, scientific concepts need to be transacted through activities and experiments. Learners should be engaged in learning principles of science through familiar experiences (NCF-2005).Therefore, professional preparation and development of teachers of science should move teachers towards developing a generative perspective. Teachers' knowledge of teaching - learning in this meaning makinggenerative framework is not found in textbooks or with the "experts"; rather, knowledge about teaching learning of science is personally created and socially mediated. This becomes important in the light of the argument that teachers make sense of their teaching worlds in the perspective of their prior knowledge of teaching, learning, and curricular approaches in a formal as well as in an informal environment. Professional development in constructive paradigm promotes the predisposition towards inquiry into the interpretation of educational situation [6]. Learning about teaching involves continuously conflicting and competing demands on the part of the teacher. Therefore, teachers themselves need to view learning of science as knowledge to be constructed by learners rather than a bundle of facts and principles to be 
transmitted to the learners. It should be amply clear to them that learning science is not cramming facts and formula to be vomited in the examination hall. It is way of thinking and a way of looking at the world.

Prospective teacher education programs may be considered as the heart of science education programs in India. These programs can be classified into two main categories, viz. the practical component and the theoretical component. We are trying to put an argument that amongst all the components of teacher education programs, the school life experience program is not just one of the most important components; it has the responsibility of imbibing the theoretical debates and dichotomies and relevant contemporary understandings about the science education. In the name of maintenance of standards, universities and colleges working in the area of teacher education are increasingly settling on one or the other set format of lesson planning based upon the behaviourist paradigms of teaching-learning. These set formats, even printed in the form of lesson plan files with set number of pages for each lesson plan (20 in total for each subject), with the preset space for writing specific objectives based on Bloom's taxonomy, on fixed pre-conceived notions about how will the teaching-learning go on in the classroom are provided to the prospective teachers. For example, the prospective teachers have to write in their lesson plans the so-called correct or expected answers from the learners, that they will get. This type of practice has raised many inherent pedagogical contradictions. For so many years, the prospective teachers have also raised pertinent questions like, how can they predict the way learners are going to put their responses in the classroom; how can they be so sure that all the learners in the class would respond in the same way; is teacher the only source of knowledge; does learning involve individual efforts or it is a collaborative attempt?, etc [7].

When science learning is seen not as a straightforward process, but as interwoven multidimensional design, the practice of science becomes a more challenging task. Science in this framework is more than the content, process and inquiry; learners learn science by actively engaging in it. An active engagement involves inquiry, exploration, questioning, debates, application and reflection, leading to theory building and creation of ideas. Therefore teachers should know what learner can do for learning science, how they should be engaged in learning science and how to become flexible and inventive to develop learners' competence in learning science. It is of utmost importance for the prospective teachers to focus on what the learners will do rather than what the teacher will do in teaching learning situations.
Based on the guiding principles of NCF-2005, NCERT has developed textbooks form class I to XII. Relating the concepts with everyday life experiences a number of activities are given in the science textbooks of all classes for facilitating learners to lead into inquiry and construction of knowledge. A number of in-service training programs, both in face- to- face and distance mode have been organized to orient practicingteachers to transact the newly developed textbooks. However, we still have to do a lot for moving away from the traditional manner of conducting school experience programs for prospective science teachers. Position paper [8] on Teaching of Science recommends that the science teacher preparation curriculum should be in consonance with changing priorities and challenge of the times. Any major change in the school science curriculum should necessarily involve concomitant change in the teacher education curriculum. Inadequacy in the prospective education of science teachers cannot be compensated through in-service programs. Therefore, an urgent need to strengthen teacher education programs by facilitating prospective teachers in construction of their knowledge about the approaches for teaching- learning and pedagogy of science has been identified.

\section{Research Design}

\subsection{Research question}

- Can use of the six learning strands at planning stage empower prospective teachers for designing science practices?

- Can use of the six learning strands help them to facilitate learners at the upper primary stage (class 6-8) to engage in construction of knowledge?

- Can the learning strands help practicing science not as a culture of rote memorization, drill and practice but as the inherent needs from the perspective of epistemology of science?

\subsection{Objectives}

1. To acquaint the prospective teachers in the application of the six learning strands at the planning stage of designing science learning experiences for the learner sat upper primary stage in science classrooms.

2. To find the effectiveness of the learning strands in science practices from the observations of the quality of teaching-learning experiences of the learners.

3. Ascertain the effectiveness of the learning strands in science practices using feedback given by the prospective teachers. 


\subsection{Hypothesis}

- Use of the six learning strands at planning stage empowers prospective teachers for designing science practices.

- Use of the six learning strands help them to facilitate learners at the upper primary stage (class 6-8) to engage these science learners in construction of knowledge.

- The learning strands help practicing science not as culture of rote memorization, drill and practice but practice but as per the inherent needs from the perspective of epistemology of science.

\subsection{Method, Sample, Tools and Techniques}

The researchers interacted with 20 prospective teachers during their pre-internship phase of teacher education program and had a critical dialogue on the importance and application of learning strands in designing teaching- learning experiences of science. This was done in the context of facilitating learners in construction of their knowledge and developing proficiency in science practices. The researchers also discussed about the inherent flexibility in the lesson designed using learning strands as compared to traditional way of using specific objectives in the lesson plan. For one week the researchers discussed how we can develop science lesson designs using learning strands instead of planning lessons on the basis of Bloom's Taxonomy. Based upon understanding gained from these discussions, the prospective teachers designed the lessons to be transacted during school experience program. Each of the prospective teachers designed their 20 lessons incorporating the idea of the learning strands. They further discussed among themselves and with the researchers to get it modified in the light of true nature of the learning strands. These well modified lessons were transacted in real classroom situations in twenty different schools of Delhi. The schools were chosen from the urban as well as from the rural areas and catered to different segments/strata of the society. Schools were of three categoriesgovernment, aided and private schools. In all, 400 lessons were transacted by the prospective teachers in their respective schools. The sample comprised boys and girls both studying in Classes 6-8.The researchers observed some of these lessons transacted in the class.

As far as tools are concerned, all the three tools were used such as questionnaire, interview schedule and observations. The researchers developed a questionnaire comprising sixteen questions correlating the six learning strands. Out of sixteen items, eight items were of yes/no type and the remaining eight were open-ended questions. The purpose of these eight open-ended questions was to get qualitative feedback from the learners.

The prospective teachers were suggested to write their own reflections on the use of learning strands in their lesson design and about their teaching-learning experiences. For this, each prospective teacher maintained a reflective journal to note down their reflections on daily basis.

The effectiveness of the learning strands in empowering the prospective teachers for science practices has been investigated from the responses of the learners at the upper primary stage in terms of quality of questions raised by the learners and feedback received from the prospective teachers. To ascertain the effectiveness of learning strands, interview of teachers was conducted. The perception developed from these interviews was enriched by using written feedback from the prospective teachers to have an in depth understanding about effectiveness of the six learning strands. To ascertain this understating the observations taken by the researchers were considered.

\subsection{Data collection}

A Questionnaire was administered to the 723 learners at upper primary stage (Classes 6-8) by the twenty prospective teachers during the transaction of their twenty lessons in each of their school (see Table 1).

Table 1. Questionnaire

\begin{tabular}{|c|c|c|c|}
\hline Number & Items & Yes\% & No\% \\
\hline 1 & $\begin{array}{l}\text { Did you want to } \\
\text { know something } \\
\text { more on the topic? }\end{array}$ & 68 & 32 \\
\hline 2 & $\begin{array}{l}\text { Did you look for } \\
\text { other resources of } \\
\text { learning such as } \\
\text { books, internet or } \\
\text { discussed? }\end{array}$ & 79 & 21 \\
\hline 3 & $\begin{array}{l}\text { Did you ask any } \\
\text { question being } \\
\text { discussed in the } \\
\text { class? }\end{array}$ & 67 & 33 \\
\hline 4 & $\begin{array}{l}\text { Did you want to } \\
\text { know answer of } \\
\text { some more } \\
\text { questions coming } \\
\text { to your mind? }\end{array}$ & 46 & 54 \\
\hline 5 & $\begin{array}{l}\text { Did you share your } \\
\text { observations with } \\
\text { peers, parents? }\end{array}$ & 67 & 33 \\
\hline 6 & $\begin{array}{l}\text { Do you think } \\
\text { yourself as a } \\
\text { learner of science? }\end{array}$ & 80 & 20 \\
\hline
\end{tabular}




\begin{tabular}{|l|l|l|l|}
\hline 7 & $\begin{array}{l}\text { Do you think you } \\
\text { can contribute to } \\
\text { the progress of } \\
\text { science? }\end{array}$ & 63 & 27 \\
\hline 8 & $\begin{array}{l}\text { Did you plan } \\
\text { /perform } \\
\text { activity to find } \\
\text { answer of your own } \\
\text { question? }\end{array}$ & 61 & 49 \\
\hline
\end{tabular}

The prospective teachers organized and analyzed the collected data for their own reflections on teaching learning experiences. They also submitted their qualitative feedback on their experience of teaching - learning process. Each prospective teacher was interviewed using the unstructured interview schedule designed by the researchers after completion of their school life experience program was over. Researchers' observations of the classroom transaction of the lesson design developed using the six learning strands were also taken into consideration. Finally, the researchers organized all the data and analyzed them in order to study effectiveness of the use of the six learning strands at planning stage to empower prospective teachers for science practices.

\section{Findings and Discussion}

To understand the teaching learning contexts in the light of learning strands, eight items were used. Responses of 723 learners belonging to 20 different schools, and studying in Class 6-8 were collected for the same. Table 1 depicts yes/no type items given to the learners.

The responses to the item numbers one and two clearly indicate that the prospective teachers were successful in generating interest and curiosity in their learners and intrinsically motivating them to participate in science learning process. The item number three shows that in contrast with the common observations in science learning classrooms, the learners were able to raise questions on the topic discussed. Another contrast to the common science learning practices was observed in item number five where we can see that a huge percentage of the learner responses indicate sharing of 'what they learn' with others. A good eighty percent of learner's responses in item number six show that they are feeling as a learner of science. This indicates that they consider themselves as the authentic part of the teaching learning process of science and not just an external part which has to answer some questions in the examination. The seventh item also supports this identity formation by the science learners that they are and can be an authentic part of not just leaning science in the science classrooms but also in the development of science in future. For this purpose the learners also need to develop their own activities and experiments in science. This aspect is clearly supported in the responses to item number eight. The response to the item number 4 above needs our special attention. This higher percentage of "no" in the responses may be understood as the higher number of learners feeling satisfaction with the nature of teaching learning processes designed for them and the way the lesson was being transacted by the prospective teachers.

The above discussion related to the eight items shows that the learning strands help practicing science not as culture of rote memorization, drill and practice but as per the inherent needs from the perspective of epistemology of science.

The classroom observations done showed a type of chaos on the first look as most learners were not just sitting and listening to their teachers. They were as much part of the discussions in the classrooms as their teachers. The authority that the teacher usually exercises in the class was missing here. Instead the teacher was seen moving to their seats, finding the problem that the learner was facing, trying to scaffold the same wherever necessary. A lot of noise in the classroom was also observed. Some of the teacher educators and colleagues involved in the School Experience Program did not agree with this mode of working. As per their view this was a classroom management issue. Some of them were of the opinion that the prospective teacher is not able to manage the classroom properly. At an extreme opinion, they also said this is undisciplined classroom. In these observation we need to revisit our own notions of how do we want our learners to participate in the teaching learning process - sitting quietly and listening, responding to the questions raised by the teacher and best forms of managing observed by the observer or something that had been described above giving an evidence that the learner is authentic part of teaching learning process. The answer for us is in the second choice. It is also important to mention here that the same prospective teachers were also teaching other subjects using the traditional modes of planning their lessons. Most of the observations shared here about the science classrooms were not part of those classes.

Going further related to other aspects of science culture, Communication is one the important aspect of science practices. The position paper on science considers this aspect.

As language is more than a way of labelling things around us; it is a tool that helps us to conceptualise, Language adds meaning to, and aids in interpreting our experiences. Researches on the role of language in science learning has led to better understanding of metaphor and analogy, and of how meaning is drawn from science activities [8]. This aspect was taken care of when the 
prospective teachers encouraged their learners to write report of the activities carried out in the class in their own words. It showed learners way of viewing the world and their communication skills. Responses of three learners form a total of given below as example. The examples demonstrate learners' understanding of the concepts when they were involved in carrying out activities and given

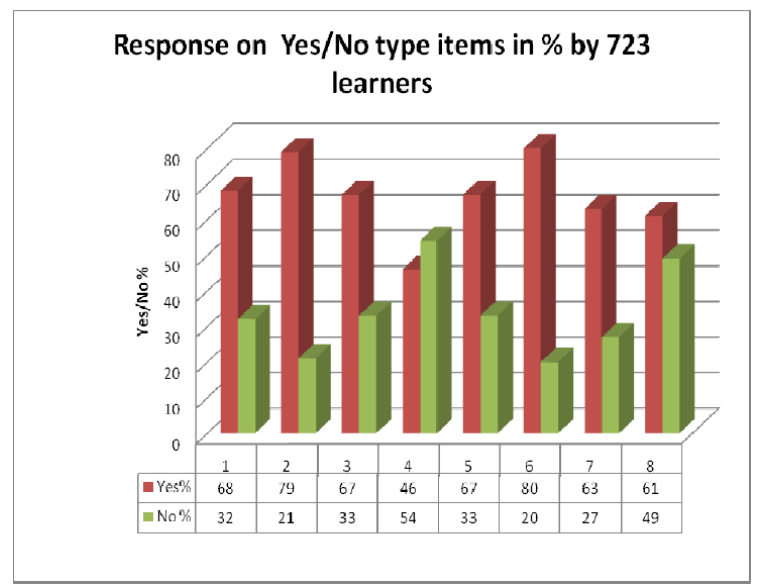

Figure 2. Response on Yes/No type items in \% by 723 learners

freedom to perform activities in the way they liked to learn. Learners could communicate their understanding through drawing, writing and raising questions.

$(1.3 .35)$



Figure 1. Example of Learner Diagram 1

$(1.4 .27)$





$$
\begin{aligned}
& \text { तो ram थे उUlb बही जलेगा } \\
& \text { because } 4 \text { इसका एक तार जो } \\
& \text { है वाa cornact } n \text { नही है। और }
\end{aligned}
$$

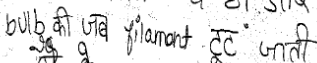

$$
\begin{aligned}
& \text { है तो Julb glow वही करती }
\end{aligned}
$$

Figure 4. Example of Learner Diagram 2
$(1.6,0)$



Figure 5. Example of Learner Diagram 3

These findings support that 'Reading and writing comprise over half of the work of scientists and engineers'. This includes the production of various scientific representations - such as tables, graphs, and diagrams - as well as other forms of communication such as giving conference presentations and speaking to the public and other stakeholders. The reading and writing that scientists do help them better understand scientific ideas and communicate their research to their colleagues and to the public. Thus, K-12 learners of science should have substantial and varied experiences with reading, analyzing, writing, and otherwise communicating science so that they too can deeply engage with disciplinary core ideas and crosscutting concepts while exploring practices associated with scientific reading and writing [9].

These evidences suggest that the inherent flexibility of the learning strands provides ample scope to address learning needs of a diverse group of learners in a science class. It also shows that if learning space is provided, which is the characteristic feature of the lesson design using the six learning strands, learners at the upper primary stage could generate thinking about the topic being transacted in the class and they could bring their previous experience regarding the scientific phenomenon being discussed in the class. They started connecting classroom learning with their everyday life.

It also ascertains that learning occurred in a shared social context of the learners, peers and family members. The experience of learners learning with only facilitation form their teachers helped them to construct their knowledge. The analysis of the qualitative responses underlines that the learners not only asked relevant questions, but also many exciting questions that are not given in their textbooks and about which educationist think they would be beyond the comprehension level of the learners of upper primary stage. Some of these questions are given below:

Questions

Why Smoke rises up?

What is the difference between air and wind? 
How do we use Sailboat to move in the opposite direction of the wind?

How does our heart work?

Is the size of cell in an elephant body is larger?

How many cells are found in an ant body?

Why does a magnet attract only iron and not plastic and paper?

How does a magnetic compass work and show the direction?

Do the conductors get charged on rubbing?

What type of animal is Rhino - herbivores, carnivorous or omnivorous?

Can we push water?

Can we magnetize every iron material?

How is a magnet formed?

In which plant the transportation of food is prohibited?

Why does sky not give snow everywhere?

How does the Moon rotate?

How do I listen sound of voice of my relative residing in other country on my cell phone?

How do animals talk to each other?

How are soil formed?

It is imperative to say that the classroom environment created by the prospective teachers allowed the learners to raise such questions coming to their mind. Teaching learning situations were driven by learners' questions, rather than teachers' instructions.

Transaction of science lesson applying learning strands provoked interest and curiosity both, among the learners to know something more beyond what is given in the science textbook and beyond what is discussed in the class. Learners were noticed to be more reflecting, participating and engaged with science as a way of knowing and thinking. Most of them tried to validate their knowledge by performing further activities on their own, talking to their parents and searching the relevant websites.

Learners attempted to create their knowledge of scientific concepts and mediate it socially. They tried to enhance their learning by collaboration and discussion with others, by performing the same or similar activities, observing and drawing conclusions based on the data collected by them. It shows enhancement of their epistemic understanding of science. They learned to generate evidence to collect information about many natural phenomena.

The analysis of the responses underlines that the learners not only asked relevant questions, but also they could think scientifically about the topic that had been specified in formal classroom learning environment in the form of activities and arguments. To some extent they were found reflecting on science as a way of knowing and thinking. Prospective teachers observed that there were no boundaries in the thinking of upper primary stage learners as they could think in terms of out of the box situations, ideas and questions.

Observing the questions raised, many of which were beyond the so called syllabus of the upper primary stage, by the learners, and prospective teachers realized that they should use other reference books also in addition to the textbook in order to help learners. Prospective teachers started strengthening their content knowledge before going to their classrooms so that they could facilitate learners to find answer to their own questions and plan activities. They found that learners got themselves engaged in search for meaning out of their personal experiences.

An important implication of the study is that curriculum planners can take a hint from the curious questions of the learners which the lesson designed on the basis of learning strands can elicit from them. The study shows that many questions asked by learner fall in the curriculum of higher classes. This area of learning is usually conceived beyond the comprehension level of learners at upper primary stage. Curriculum planners need to revisit their criteria of inclusion of a particular concept in the syllabus of a given class. Leading learners into inquiry in the search of their own questions can be a firm step towards construction of knowledge.

\section{Conclusions}

'Can a teacher cover the syllabus if she/he pays attention to the questions raised beyond the textbook?' This question had been asked by many practicing teachers when they are introduced to the flexible learning designs. This question can be answered by asking another question i.e., 'What do we want our learners to gain and society also to benefit out of science classrooms?'. The answer is definitely not bounded to cramming textbook material and repeating it in the examinations and moving on. We want our learners to develop independent thinking and creative abilities so that they can contribute to the development of science also. For this to happen, the culture of science needs to be practiced in the science classroom itself. As mentioned earlier also, the learners have been observed to have engaged themselves in search for meaning out of their personal experience using various resources, practicing science with others, raising relevant questions and trying to find their answers. All this is an expected part of practicing science in accordance with the culture of science through which science actually develops.

The professional preparation and development of teachers of science should move teachers towards developing a generative perspective. The study shows that the six strands of learning suggested by Bell in the informal setting can be applied in a formal set-up effectively for teaching- 
learning of science at upper primary stage in India [4]. There are evidences suggesting that the inherent flexibility of the learning strands provides ample scope to address learning needs of a diverse group of learners in a science class.

Using the six learning strands to plan their science lesson, prospective teachers could allow more choice and control over what learners wanted to know and engage them in inquiry to learn various concepts of science. One of the interesting findings of the study is that most learners think themselves as learners of science and able and capable to contribute in the development of science. We recommend the six learning strands as a resource for planning science learning experiences in the teacher education programs.

\section{References}

[1] National Council of Educational Research and Training, "National Curriculum Framework-2005,"New Delhi, 2005.

[2] R. A. Duschl, H. A. Schweingruber, and A. W. Shouse, Taking Science to School: Learning and Teaching Science in Grades K-8. 2003.

[3] R. A. Duschl, H. A. Schweingruber, and A. W.Shouse, Taking Science to School: Learning and Teaching Science in Grades K-8. Washington, D.C.:THE NATIONAL ACADEMIES PRESS, 2007, p.404 pages.

[4] P. Bell, B. Lewenstein, A. W. Shouse, and M. A. Feder, Learning Science in Informal Environments: People, Places, and Pursuits. Washington, D.C.: THE NATIONAL ACADEMIES PRESS, 2009, p.352.

[5] S. Michaels, A. W. Shouse, and H. A. Schweingruber, Ready, Set, Science!: Putting Research to Work in K-8 Science Classrooms. Washington, D.C.: THE NATIONAL ACADEMIES PRESS, 2007, p. 220.

[6] A. K. Jha, "Pedagogic Content Knowledge and Process Dichotomy: Implications for Constructivist Teacher Education," Indian Journal of Eucation Research Experimentation and Innovation, vol. 1, no. 4, pp. 1-10, 2011.

[7] S. Prabha, A. K. Jha, and R. Kumar, "Efficacy of Learning Strands in Science Education: Implications for Pre-service Teachers and Teaching in India," in Canada International Conference on Education2012, 2012, pp. 158-152.

[8] National Council of Educational Research and Training, "National Focus Group on Science Teaching," New Delhi, 2006.

[9] P. Bell, L. Bricker, C. Tzou, T. Lee, and K. Van Horne, "Exploring the Science Framework," 2012. 